\title{
Spirituality in the Occupational Therapy Community Fieldwork Process: A qualitative study in the South African context
}

\author{
Thuli Godfrey Mthembu, BSc OT (UWC), MPH (UWC) \\ $\mathrm{PhD}$ candidate, Lecturer, Department of Occupational Therapy, University of the Western Cape
}

Lisa Wegner, BSc OT (Wits), MSc OT (UCT), PhD (UCT)

Associate Professor, Department of Occupational Therapy, University of the Western Cape.

Nicolette Vanessa Roman, PhD (Psy) (UWC), MACFS (UWC)

Professor, Child and Family Studies, Department of Social Work, University of the Western Cape

Background: Spirituality is an integral part of communities; it is influenced by the environment and provides meaning and purpose to occupations. However, spirituality has been a controversial concept within the profession of occupational therapy and is the cause of much debate with a range of viewpoints emerging among students and educators practising in communities. However there has been limited research carried out on spirituality in the community fieldwork process in a South African context.

Methods: An exploratory-descriptive qualitative study was used to explore occupational therapy educators' and students' perceptions regarding spirituality in the community fieldwork process, using focus group discussions which were thematically analysed.

Results: Three themes emerged: students' exposure to spirituality in community settings, community development strategies and perceived enablers of spiritual occupations. The results indicated that community entry, asset-based community development and empowerment strategies of locality development seemed to assist students in their exposure to spirituality in communities. These strategies enhanced students' understanding of the role of spiritual occupations in which community members collectively engage in order to improve their social participation and connectedness.

Conclusions: The findings provided an understanding of and insight into spirituality in the occupational therapy community fieldwork process. These findings may help us to understand the significance of experiential learning regarding spirituality in communities.

Key words: community development, occupational therapy; spirituality; fieldwork

\section{INTRODUCTION}

Spirituality has been a controversial concept within the profession of occupational therapy and a cause of much debate and a range of viewpoints. The Canadian Model of Occupational Performance and Engagement defines the concept of spirituality as the core of the model and integrates it into occupational therapy practice'. However, Duncan still highlights the fact that this definition is inconsistent, although he agrees that '....its position is justified, as spirituality resides in persons, is shaped by the environment and gives meaning to occupation ${ }^{2: 83}$. Therefore spirituality is considered as one of the significant elements of the holistic approach that promotes the health, quality of life and well-being of individuals, groups and communities in the South African context. Spirituality refers to a dynamic and intrinsic aspect of humanity through which persons seek ultimate meaning, purpose and transcendence, and experience relationships to self, family, others, community, society, and nature, both significant and/or sacred"3:646. Spirituality is expressed through beliefs, values, traditions, and practices ${ }^{3: 646}$. There have been studies in the literature reporting the benefits of considering spirituality in health care. The benefits of spirituality in health include stress control, providing better coping mechanisms, richer social support, hope and improved compliance; it engenders positive thinking, builds trust, social capital, integration and greater psychological resources, and strengthens personal values and worldview ${ }^{4,5,6}$. Additionally, previous studies indicate that spirituality has positive effects on social, mental and emotional health. These benefits seem to provide human beings with meaning and purpose in life. Hence, human beings tend to turn to their beliefs and values to assist them to cope with any life crisis, hardships and illnesses because of the benefits gained from their spirituality.

\section{Literature review}

There have been a number of studies that highlighted the importance of spirituality in community development that appeared to promote social change in individuals and communities ${ }^{7,8,9}$. Community development is "the process in which members of a community attempt collaboratively to promote what they consider to be their collective well-being through unity of action" "7:321. Similarly, it has been shown that spirituality in community development "seeks to remove those things that suppress the expression of individual and collective empowerment"7:324. It is highlighted that spirituality shapes our relationships with others and our environment as well as our interconnectedness, which, in turn, promotes an holistic framework. The holistic framework comprises social justice, economic fairness, human rights and ecological sustainability. Hence, the links between spirituality and community development acknowledge diversity, which indicates that power and resources (social, cultural, economic and environmental) tend to be distributed in an equitable manner to enhance interests, beliefs, practices and healthy communities through health promotion ${ }^{10}$. Chile and Simpson ${ }^{7}$ emphasise that the connection between spirituality and community development seems to promote social justice that facilitates radical transformation of community structures. This is supported by the humanitarian values that include social justice, altruism (Watson and Duncan ') and benevolence, humanism, integrity, justice, mutuality, receptivity, respect and responsibility, as well as trust (Spittles ${ }^{12}$ ). These humanitarian framework values were found to be related to spirituality and community development toward social change.

However, in their comprehensive discourse on spirituality and community development, it was found that the lack of recognition of spirituality as part of community development seems to impede 
the effectiveness and interventions of individuals and collectives ${ }^{12,13}$. This indicates that development workers did not consider the importance of spirituality, despite the fact that it seems to influence communities' understanding of their world when making their decisions and taking action. As a result, it has been reported that the "failure to recognise the centrality of their spirituality ultimately robs the poor of opportunities to tap into whatever strength, power and hope that this dimension gives them, and deprives them of the opportunities to reflect on and control how their development and spirituality shape each other"13:31-32. Additionally, Ver Beek ${ }^{13}$ points out that failure to acknowledge communities' capacity to identify their own values and priorities seems to influence their ability to reflect on how spirituality might shape their future. It has been reported that ignoring issues of gender, class and ethnicity, together with spirituality and religion, as part of community development might have an influence on how the communities express their needs. Consequently, Ver Beek ${ }^{13}$ suggests that outsiders should attempt to learn and understand the local knowledge systems which are considered to be important for various communities where they tend to do projects as part of community development. In addition the outsiders may engage in dialogue with the community, apply their observation skills and engage in local practices of the community. Individuals and collectives should be provided with opportunities to reflect on their beliefs and their practices which are related to spirituality, as well as options which may preclude or help in achieving their communal goals. Similarly, communities involved in community development should be allowed to decide on their own goals and how they will attain them with outsider facilitation. Ver Beek ${ }^{13}$ indicates that strengthening a community's actions may enhance community participation and promote its spirituality. Despite the significance of spirituality in community development however, little is known about spirituality in community development and occupational therapy fieldwork education.

Community development is regarded as an integral part of promoting transformation in higher education to contribute to social capital and prepare graduates to be active members of the communities in which they live and work. This aligns with the goals ( 8 and 9) of the White Paper on the Transformation of Higher Education in South Africa ${ }^{14: 14}$. These goals include:

"To promote and develop social responsibility and awareness amongst students of the role of higher education in social and economic development through community service programmes" and "To produce graduates with the skills and competencies that build the foundations for lifelong learning, including critical, analytical, problem-solving and communication skills, as well as the ability to deal with change and diversity, in particular the tolerance of different views and ideas"

As a result, occupational therapy fieldwork education introduces undergraduate students to individuals, groups, families and communities using a population approach ${ }^{15}$ so that they may learn and understand the impact of what people do on daily basis regarding their health and well-being, particularly living in areas affected by poverty ${ }^{16-18}$. Community is defined as a "group of people with diverse characteristics who are linked by social ties, share common perspectives, and engage in joint action in geographical locations or settings" 19:1929. Community development is a "process of organising and supporting community groups in identifying their health issues and strategies...; in the process the community becomes self-reliant, allowing it to gain decision-making power as a result of developed strategies and actions"20:1. It has been indicated that community members play an important role in driving their priorities and the implementation of actions to bring about social change ${ }^{21}$.

For instance, occupational therapy students in one of the universities in the Western Cape Province, South Africa, were introduced to three community development approaches as part of their community fieldwork education ${ }^{22}$. These included locality development, social planning and social action ${ }^{23}$. Locality development involves broad participation in the local community in identifying goals and actions. Conversely, social planning is the consideration of a top- down approach whereby the professionals and experts identify and plan actions on behalf of the community. The third approach, social action, is when the disadvantaged communities advocate for justice and equal rights within their broader community. It has been shown that application of both community development approaches and health promotion seemed to assist occupational therapy students from one of the universities in the Western Cape Province to work with individuals and communities ${ }^{22}$. The partnership between students and communities appeared to be an enabler that facilitated identification of community needs and maintained community participation and motivation ${ }^{22}$. Health promotion is "the process of enabling people to increase control over and to improve their health" 24 . The health promotion perspective is used in occupational therapy to promote empowerment of community members through education and skills development ${ }^{24,25}$. This concurs with Micallef's ${ }^{26}$ and Laverack and Mohammadi's ${ }^{27}$ explanation of empowerment, namely the process by which community members gain greater control over decisions and actions affecting their health. The Ottawa Charter of Health Promotion promotes the use of five strategies, including building healthy public policies; creating supportive environments (culture, social, economic, political, physical and spiritual); developing personal skills; strengthening community actions and reorienting health service ${ }^{28}$. Regarding the strengthening of the community's actions strategy, occupational therapy students are taught the importance of occupation-based practice in order to meet the immediate needs of all stages of development through engagement in meaningful and purposeful occupations. In addition, the students use occupational science to guide their understanding of humans as occupational beings who have occupational rights to participate in daily occupations. Hence occupational therapy models like the Person Environment Occupation Model seem to enhance occupational therapy students', educators' and clinicians' understanding of the interaction and interdependence between the person, the environment and the occupation ${ }^{29}$.

Occupational therapy students are placed in diverse communities for six-week fieldwork placements as part of their fourth-year course. The occupational therapy students learn how to promote an holistic approach which comprises the physical, mental, social and spiritual components of the community members ${ }^{29-32}$. In addition, the occupational therapy students are taught to use community fieldwork processes and community development, as well as other approaches, to guide them in their community fieldwork practice $^{30-32}$. One of the main outcomes of the community fieldwork process is that students should be able to demonstrate critical analysis in applying knowledge and skills in community contexts using a population-based approach ${ }^{15,30}$. Similarly, the students are expected to apply the strategies of community entry, needs assessment and needs analysis so that they might address the community's needs 22,30-34. In addition, the students and community members employ the Assets Based Community Development (ABCD) strategy to map the assets around the community so that these resources may be identified and located, together with relevant organisations, with the aim of formulating networks within the communities ${ }^{35,36}$.

Several studies have revealed that both community fieldwork education and practice seemed to omit spirituality ${ }^{37-38}$. Regarding community fieldwork practice, the occupational therapy students learn to apply their knowledge and understanding of the community fieldwork process by engaging individuals and communities in planning and implementation of the community projects ${ }^{27,32-35}$. Therefore, Kang ${ }^{36: 96}$ refers to the community projects as 'sociospiritual experiments' because they seem to be community-driven and aim to reclaim local culture, local economy and local ecology in a spirit of ethical living, inclusiveness and spiritual well-being for all. These community-driven projects may be used in order to facilitate collective empowerment, community participation and engagement to bring about change in communities ${ }^{27,32-35}$. Despite the fact that spirituality has been widely considered as a significant element of an holistic approach in community development and occupational therapy practice, there has, however, been limited 
research on spirituality in the community fieldwork practice in a South African context. Occupational therapy educators and students seem to face challenges in integrating spirituality and to be spiritually sensitive while providing occupational therapy services to diverse communities. In the occupational therapy profession little research has been done to explore the perspective of occupational therapy educators and students regarding spirituality in community fieldwork practice. Exploring educators' and students' perceptions can contribute significantly towards insights regarding spirituality in community fieldwork practice. Therefore the current study primarily aimed to explore occupational therapy educators' and students' perceptions regarding spirituality in the community fieldwork practice. Using the findings of this study, conducted on the perceptions of one university employing a community fieldwork process, can guide discussions of how spirituality can be integrated into community fieldwork education.

\section{Research design and methods}

An interpretive exploratory-descriptive qualitative approach was used in order to obtain a deeper understanding of the phenomenon of spirituality in community fieldwork practice ${ }^{39,40}$. The interpretive research values knowledge gained through social constructions, including language, consciousness and shared meanings, and emphasises the importance of the relationship a researcher has with the phenomena ${ }^{40}$. The population of the study comprised occupational therapy educators and students from one of the universities in the Western Cape Province, South Africa. In this study, purposive sampling was used to recruit the participants for the focus group discussions (FGDs) ${ }^{4}$. The first group, I I thirdyear students, were invited to be part of the study. The second group comprised seven third-year students who volunteered to participate in the study. A third group of participants was obtained by inviting I I fourth-year students. All undergraduate occupational therapy students were registered in third and fourth year levels. Both females and males were selected for the study (Table I). The last group comprised nine occupational therapy educators who taught and supervised students in general fieldwork and those who specifically supervised community fieldwork practice. The participants were contacted and invited by one of the authors to take part in the study.

Table I: Characteristics of the participants

\begin{tabular}{|l|c|c|c|}
\hline \multirow{2}{*}{ Variables } & \multicolumn{2}{|c|}{ Gender } & \multirow{2}{*}{ Total } \\
\cline { 2 - 3 } & Female & Male & \\
\hline Educators* & 8 & I & 9 \\
\hline Level of education: & \multicolumn{2}{|c|}{} \\
\hline B OT & $\mathrm{I}$ & 0 & 1 \\
\hline Masters & 4 & 0 & 4 \\
\hline PhD & 3 & 1 & 4 \\
\hline Students* & 27 & 2 & 29 \\
\hline Level of study & & & \\
\hline Third year students & 18 & 0 & 18 \\
\hline Fourth year students & 9 & 2 & 11 \\
\hline
\end{tabular}

*Hereafter, 'participants' refers to both educators and students

\section{Data collection and analysis}

Four FGDs, which lasted between 50 and 80 minutes each, were conducted between February and July 2015. An interview guide was used to elicit participants' perceptions regarding spirituality in the community fieldwork process. All FGDs were audio-taped and transcribed verbatim. Subsequently, all the transcripts were imported and organised in Atlas.ti7 software and analysed thematically ${ }^{42}$, in conjunction with 'noticing collective thinking' (NCT) ${ }^{45}$. The first author (TGM) used the six steps of thematic analysis which guided the analysis through the process of 'familiarisation and noticing' ${ }^{42,43}$. This process relates to reading through the transcripts several times prior to analysing them in order to make sense of the data. Secondly, initial codes were generated based on the FGD transcripts which were relevant to the research scope while reading line by line. Additionally, some of the codes were created using in-vivo coding by capturing participants' words as codes. Thirdly, themes were searched from the families (categories) created in Atlas.ti 7. Fourthly, themes were reviewed based on the coded extracts and full data set and some of the themes were collapsed. In the fifth step, themes were named using exact words from the respondents as part of in-vivo coding. The sixth step involved the written recording of the findings, which was done through analytic narrative and data extracts. Two authors ( $L W$ and NVR) monitored the data analysis to ensure that the quality was maintained and consensus about the findings was reached.

\section{Trustworthiness of the study}

Trustworthiness was established and ensured by means of credibility, transferability, dependability and confirmability ${ }^{44}$. Credibility was established through prolonged engagement as the researcher spent sufficient time with the participants during data collection. Peer debriefing was conducted with LW and NVR to discuss the results of the study until consensus was reached. Member-checking was ensured through continuous validation with the participants to confirm that the transcriptions, categories, interpretations and conclusions were a true reflection of the participants' perceptions. Additionally, an interview guide (Table II) was used for the FGDs for consistency throughout the interviews. Transferability was established through the provision of thick description of the data and context. Dependability was ensured by providing dense descriptions of the context, the sampling method and characteristics of participants, data collection and analysis. An inquiry audit was used to ensure that the researchers adhered to the plans of the research. Confirmability was established through an audit trail whereby the research process was honoured and researchers reached consensus about themes that emerged from the analysis.

\section{Table II: Focus group interview guide}

\begin{tabular}{|c|l|}
\hline Item & Questions \\
\hline $\mathbf{I}$ & $\begin{array}{l}\text { Could you please tell me about how you think spirituality } \\
\text { comes out in the community fieldwork process? }\end{array}$ \\
\hline $\mathbf{2}$ & Could you give me examples from your own practice? \\
\hline $\mathbf{3}$ & $\begin{array}{l}\text { What are the strategies of community development that } \\
\text { seem to be important for spirituality in community settings? }\end{array}$ \\
\hline $\mathbf{4}$ & $\begin{array}{l}\text { How did these strategies assist you to see spirituality in the } \\
\text { community? }\end{array}$ \\
\hline $\mathbf{5}$ & $\begin{array}{l}\text { What activities do you think helped you to see that } \\
\text { community members value spirituality? }\end{array}$ \\
\hline $\mathbf{6}$ & $\begin{array}{l}\text { Have you ever had an experience of seeing where } \\
\text { spirituality plays an important part in another's life or your } \\
\text { life? }\end{array}$ \\
\hline $\mathbf{7}$ & $\begin{array}{l}\text { What exactly are the communities doing that will tell you } \\
\text { now that they are considering spirituality as important to } \\
\text { them? }\end{array}$ \\
\hline $\mathbf{8}$ & $\begin{array}{l}\text { What activities do you think can assist students and } \\
\text { educators to learn more about spirituality? }\end{array}$ \\
\hline
\end{tabular}

\section{Ethical consideration}

Ethics approval to conduct the study was obtained from the University of the Western Cape Research Ethics Committee (14/4/I8). The participants' confidentiality and privacy were ensured throughout the study. Participants were also informed about the purpose of the study and about withdrawal from the study without any repercussions, to which they gave written consent. 


\section{RESULTS}

The following three themes with nine categories were identified: students' exposure to spirituality in community settings, community development strategies and perceived enablers of spiritual occupations. Table III presents the themes and related categories.

\section{Table III: Themes and categories}

\begin{tabular}{|l|l|}
\hline THEMES & CATEGORIES \\
\hline $\begin{array}{l}\text { Students' exposure } \\
\text { to spirituality in } \\
\text { community settings }\end{array}$ & $\begin{array}{l}\text { - Exposure in communities } \\
\text { - Improvement of students' self-awareness } \\
\text { - 'Journaling" facilitated students' } \\
\text { reflections }\end{array}$ \\
\hline $\begin{array}{l}\text { Community } \\
\text { development } \\
\text { strategies }\end{array}$ & $\begin{array}{l}\text { - “Community entry helps" } \\
\text { - Asset-Based Community Development } \\
\text { (ABCD) }\end{array}$ \\
\hline $\begin{array}{l}\text { Perceived enablers of } \\
\text { spiritual occupations }\end{array}$ & $\begin{array}{l}\text { - Empowerment strategy } \\
\text { - Motivation from occupation } \\
\text { - Community project }\end{array}$ \\
\hline
\end{tabular}

\section{Students' exposure to spirituality in community settings}

This theme highlights the participants' perceptions about how students were exposed to spirituality within community settings. The participants expressed that the use of the community fieldwork process provided the students with an opportunity to have an understanding of spirituality. Additionally, the participants commented on the duration of six weeks in community settings as an enabler for students to learn about the communities and their spirituality.

"The use of community process in communities exposes the students to it [spirituality] .... they [students] talk to the concepts of spirituality that exist in a community." (Educator 3)

"Being in community for six weeks, gave me an opportunity to know the community to the point that I was able to understand their spirituality, as they were engaging in spirituality on a daily basis and they appeared to be uplifted. I tried to be part of the community by experiencing their spirituality in order to be uplifted and positive." (Fourth-year student 5)

Research confirms that students' experiential learning through taking part in community activities seems to be an important method for contributing to both the cultural and the actual experience of spirituality as an important part of communities ${ }^{45}$. Therefore, the findings of the current study suggest that students in community settings should be allowed to experience personal spiritual growth and deepen their understanding of spirituality. As a result, the students may have an opportunity to enhance their confidence in working with community members of diverse spirituality.

One of the components of spirituality that was evident in the discourse of the participants was self-awareness. The participants believed that the community fieldwork process enhanced students' self-awareness as they were able to learn about themselves. Furthermore, it appeared that the community fieldwork process was an enabler for students to understand their belief systems and spirituality.

"Students learned about themselves as persons and professionals through engaging with different communities. This exposure had to happen so that students may write anything down. I think that the exposure to learning experiences is very different in the community process." (Educator 3)

"The community process allows students to get to know more about themselves as occupational beings. Students learned to relate to community members and the different people living in the community. Furthermore, the students needed to become aware of who they are regarding their belief systems and their spirituality." (Educator 6)

The present findings seem to be consistent with other research in social work which suggests that 'practitioners and students should understand their own spirituality and be open to others' understandings of spirituality ${ }^{\prime 45: 74}$. Hence, Phillips ${ }^{45}$ emphasises that self-awareness seems to be an effective skill for enhancing community workers' approach to consider spirituality in a community setting. Additionally, practitioners may learn to communicate with community members with empathy and without judgement, and by being more open to, and aware of, the spiritual dimension of communities.

The participants indicated that being in the community setting assisted them to have an understanding of certain elements of spirituality to which they were exposed. According to the participants, the understanding of the elements of spirituality enables them to connect with community members.

"Basically, you become aware of the various aspects of spirituality that you might engage in and be connected to it [spirituality]." (Fourthyear student 5)

The findings of the current study corroborate Knudson's findings ${ }^{46}$, which state that students' exposure to diverse communities tends to help them to use their opportunities to apply knowledge and skills learned in classroom. Hence, Knudson's ${ }^{46}$ participatory action research revealed that students' exposure enhances the importance of rationality and the spiritual dimensions of local community. This suggests that students seemed to learn more when they work together with communities.

Participants reported that journaling was an effective strategy that appeared as an enabler for enhancing students' understanding of spirituality in community settings. Additionally, the participants noted that there was an improvement in students' abilities to write journals. It appeared that the students who were placed in community used their journals and the community fieldwork process as enablers to enhance their self-reflection skills. The participants mentioned that personal and professional developments were enhanced due to writing the journals.

"The community process allowed proper journaling which facilitated students to be able to journal in that depth where they start looking at what they have done, what they have seen, and how it affects who they are as professionals." (Educator 3)

"This is the process whereby the students identify who they are regarding their belief systems and as spiritual beings. At the end of the process they often have the answer to who they are as a whole spiritual being and they also understand the community and community members as individuals within the community." (Educator 6)

The above findings are consistent with Knudson ${ }^{46}$ who reported that students' journaling promotes engagement in critical selfreflection about their identity locations, as well as how they experience these within community settings. Therefore, the students' journaling in community settings should be enhanced so that they may learn about themselves and others' spiritual needs.

\section{Community development strategies}

This theme contextualises how community development strategies were perceived as enablers of spirituality in community settings in which occupational therapy students were placed to practise service learning. According to Tareen and Abu Omar ${ }^{34}$, community entry is a prelude to any action that occurs in a true partnership with the community. Participants reportedly used community entry as an enabler for integrating spirituality in the community fieldwork process. Additionally, the participants confirmed that they entered the community with open minds in order to understand the community and the differences existing in the community. The participants highlighted that their theoretical knowledge of community development and the community fieldwork process adequately prepared them to have insight into how communities function. Similarly, participants shared that they employed community entry in order to enhance their understanding of spirituality in communities and to be familiar with community members. 
"The community process promotes community entry and orientation so that they [Community members] accept you....." (Third-year Student I).

The participants further indicated that the community entry was one of the community development strategies that was perceived as an enabler that assisted them to establish connections which led to collaborative partnerships with the communities. Similarly, the participants indicated that the community entry enabled them to feel that they were part of the community.

"Community entry helped me; while in the community, you need to make friends, you also need to become part of the people in order to experience what they do on a daily basis and be one of the community members. It [Community entry] also makes you aware of different facets that you personally didn't previously engage in with your spirituality. Community development assisted me to engage in their spirituality so that I can motivate them to develop and carry on as part of their internal motivation to further develop within the community." (Fourth-year student 5)

Drawing from previous studies, Asset-Based Community Development $(A B C D)$ is a process whereby communities build networking relationships, locating the assets, skills and capacities of citizens and local organisations, rather than focusing on their needs and deficits ${ }^{3,35}$. Additionally, the aim of $A B C D$ is to help people to improve their resilience, independence and well-being by focusing on what can be done through communities working together. Therefore, participants reflected on their community fieldwork process experiences and it was clear that they regarded $A B C D$ as an enabler that facilitated integration of spirituality in the community fieldwork process. ABCD's activities, such as forming networks and connectedness, were perceived as enabling individuals, groups and communities to improve their health, quality of life and well-being. According to the participants' discussions, these community members had an opportunity to experience their own spirituality as they were able to formulate the networks that helped them to access resources within their communities. The participants further noted that spirituality was an enabler and asset that facilitated a sense of connectedness among community members.

"I am thinking of spirituality in the sense that people have experienced it, as they always form networks. This is an asset for the community. I think without spirituality the networks will not be strong; therefore, identifying spirituality as an asset also creates that connectedness." (Fourth-year student I0)

Further evidence of using $A B C D$ became apparent from the participants who regarded older adults in communities as human assets, and were more spiritual. Importantly, one participant reflected on the role of older adults in communities as they were more communicative and accepting, with more tolerance for people from diverse religions.

"Spirituality is mostly found in the older adults within the community, and it's more pronounced in the older community. The other thing is that the older adults are accepting of other people with different religions." (Fourth-year student 6)

$A B C D$ strategy encourages communities to map their capacities and resources, cohesion, religious tolerance, harmony, connectedness, participation and self-worth in order to improve health and well-being ${ }^{35}$. Thus, ABCD strengthens communities' sense of belonging, finding meaning and purpose in life through spirituality. Accordingly, various studies suggest that healthcare professionals and development workers should acknowledge the spirituality of the individuals and communities where they practise in order to prevent them being irrelevant, and be more spiritually sensitive ${ }^{11,38,45}$. Chile and Simpson ${ }^{7}$ emphasise that both spirituality and community development are the vehicles for social justice and transformation in communities.

Participants noted that community members were able to take control of their lives when their spirituality was considered as a significant component of their health which resulted in collaborative partnership and empowerment. Additionally, the participants' discourse indicated that the spiritual aspect encouraged communities to work together as a team regarding community issues, particularly those related to spirituality.

"The community fieldwork process actually brought it [Spirituality] as it makes them [Community members] feel empowered. The empowerment strategy promoted community members' willingness and acceptance to do anything that was related to their spiritual aspect, and they also felt that spirituality played an important role in the community." (Fourth-year student 6)

\section{Perceived enablers of spiritual occupations}

This theme highlights the importance of spiritual occupations which promoted integration of spirituality in community settings where the participants were practising as part of community fieldwork. The theme consists of supportive environment, motivation from occupation and community projects. Supportive environment is one of the constructs, together with the person and the occupation, that influence occupational performance and engagement of individuals and communities ${ }^{25,36}$. Therefore the participants elucidated that spirituality was a core element that contributed significantly towards creating the supportive environment in communities. This meant that the environment (social) facilitated a sense of connectedness as well as altruism among community members.

"Spirituality creates supportive environments within the community, particularly if they [Community members] share the same religion, and they have a sense of connectedness amongst each other." (Fourthyear student 7 )

The participants perceived that there was a relationship between spirituality and occupation-based practice that enabled occupational engagement. According to the participants, spirituality was one of the facilitators that motivated community members to engage in the occupation of their choice that promotes health in the community.

"In occupation-based practice, we use spirituality as a means to motivate people to engage in their occupations as a part of their occupation-based practice." (Fourth-year student 5)

"If they [Community members] engage in spiritual activities, it [Spirituality] motivates and enables them to actually engage in those activities that promote their health in the community." (Fourth-year student 7)

The findings of this study are consistent with those of Wilding, May and Muir-Cochrane that spirituality was related to occupations which were life-sustaining ${ }^{47}$. Taken together, these findings suggest that spirituality seems to be the driving force that motivates and enables community members to engage in meaningful activities to enhance their health. The findings on spirituality and occupations appear to support Kang's' ${ }^{36}$ explanation about the importance of spiritual occupations among individuals, groups and communities. Thus we postulate that this result can be explained by the spiritual occupations that communities engage in as part of health-promoting activities.

Spiritual occupations are considered as diverse collective activities that communities engage in as part of human occupation, and include prayer, scripture reading, devotional practices such as singing or chanting, meditation, yoga, tai-chi, participation in communities of faith, and expressive arts $^{36}$. The participants noted that the community members tend to participate in spiritual activities such as singing hymns and praying on a daily basis prior to meeting with them. These spiritual activities were perceived as facilitators of both social interactions among the communities and connections with God. Additionally, the spiritual activities reported by the participants seemed to provide community members with opportunities to practise their religious and belief systems which enhanced meaning and purpose in their lives.

"They [Community members] were practising their religion and faith as they were singing hymns and praying, and I also engaged in their 
spiritual activities, and I felt: wow this is a good way to keep oneself motivated!".(Fourth-year student 5)

This finding corroborates Arrey, Bilsen, Lacor and Deschepper' ${ }^{48}$ findings, who reported how prayer, meditation and religious activities were used as coping strategies to adjust and accept life, by which it can be seen that community members seem to value their spirituality and religious beliefs. Additionally, this may mean that occupational therapy students and clinicians should consider the importance of spirituality and the religious beliefs of the communities.

Acts of Random Kindness (ARK) is a strategy used to highlight the importance of kindness and sensitivity among learners within the school community ${ }^{49}$. ARK is an act of acknowledging and appreciating individuals who have done something good for someone else in the school community to promote positivity among learners and teachers. Interestingly, participants' reflections have provided evidence of how they perceived spirituality within their projects, while the community resonates with the ARK strategy. For instance, one participant reflected on the ARK project that was initiated by a local primary school together with students, as part of the community project. According to the participant, the ARK project seemed to be related to the components of spirituality, particularly forming connections among the learners and teachers. Similarly, the participant noted that the ARK project appeared as a facilitator of social inclusion; kindness; sense of connectedness; social participation; harmony and Ubuntu.

Ubuntu is a traditional African concept that promotes human kindness and human relations through moral and spiritual consciousness of what it means to be human and to be in a relationship with other people ${ }^{50}$. This concept of Ubuntu was evident in the project that the participants engaged in within the school community. The participants felt that spirituality enabled social participation among learners, teachers and families in the school setting through engaging in the ARK project. These elements seemed to facilitate inclusion of spirituality in the community fieldwork process.

"The project that I was currently busy with at a primary school was Acts of Random Kindness. I could connect it [Spirituality] to the kindness because community development is aimed at social inclusion through people showing kindness to other people.... Social participation is one of those of things that linked other people and created the harmony and Ubuntu within them. That's how I experienced spirituality within the project. Doing something good for the other person promotes kindness, in that way kindness is contagious so through me doing good you also want to do good to the next person." (Fourth-year student I)

The participant further reflected on the connections between the community members as they shared the same religion. Spirituality was also perceived as a facilitator for connections which enhanced social support among the community members.

"I know they [Community members] share the same religion. The fact is that all of the community members have it [Spirituality], and they walk to each other's' houses and it is such a small community, and they are all kind, know each other and that's their spirituality as community and there is connectedness. Spirituality can also be geared towards you, as you need people and friends around you to rely on who can be part of spirituality." (Fourth-year student I)

Another participant felt that spirituality was integrated in the community fieldwork process because all the projects were meaningful and supported by the community members. Moreover, it was reported that community members were organised and focused on the priority needs, and this led all the projects to be sustainable, as they owned them. Thus, the participants felt that the involvement of community members in all processes of their projects was also strengthening the spirituality of the communities.

"Spirituality links very much with what is important for the community and meaningful to them. At the end of the day, if I look at the identified projects and everything is basically run by the community, that's what makes them so sustainable because it is strongly linked to spirituality." (Fourth-year student II)

The findings of the present study did not specifically reveal any of the community development approaches as an enabler for integrating spirituality. However, some of the assets identified as elements of $A B C D$ in community settings seemed to support Rothman et al.' ${ }^{23}$ description of locality development. This could be explained by the fact that locality development emphasises broad participation of the local community in identifying goals and actions in order to address their needs. Previous studies also showed that professionals and students are considered as enabler-catalysts to facilitate communities to address identified needs through the application of a population approach to address structural and chronic poverty problems ${ }^{15,22,27,31}$.

This is the first study in which occupational therapy educators' and students' perceptions regarding spirituality in the community fieldwork practice were explored in a South African context, and the study seems to suggest that the community fieldwork process may have the potential to enable spirituality in community settings through the use of the community fieldwork process. The findings of the study have a number of important implications for teaching and fieldwork education as well as practice. Regarding teaching and fieldwork education, the evidence from this study suggests that educators may need to introduce students to the concept of spirituality by being explicit about spirituality in the community fieldwork process. Similarly, the results of this study indicate that journaling seems to be an appropriate tool for enhancing students' learning experiences and as a self-awareness exercise which may facilitate personal and professional development. It thus seems that the findings of the current study suggest that educators may employ reflective journals to assist students and occupational therapists to learn about their spirituality as human beings.

In relation to practice, it would appear that students and occupational therapists may need to have an understanding of how to use community development strategies (community entry, $A B C D$ and empowerment) in order to enable community members to develop their meaning and purpose in life through their engagement in spiritual occupations. It is important that students and occupational therapists should be equipped and be adept with spiritual dimensions of occupations in community settings to enable communities' self-reliance and connectedness. This study was conducted with educators and students from one institution of higher learning, and the findings may not be general to other populations of educators and students. However, it would indicate that further research would be of benefit and that it would be useful to conduct further research with educators and students from other institutions with occupational therapy programmes in order to explore their views about spirituality and community. Another limitation of this study was that FGDs were used as the data collection method; it could be useful to consider journals in future studies as part of data triangulation.

\section{CONCLUSION}

The current study explored occupational therapy educators' and students' perceptions regarding spirituality in the community fieldwork process. The evidence from this study indicated that both self-reflection and critical reflection, through the use of journaling, facilitated students' self-awareness and learning about spirituality as part of the community fieldwork process. Community entry, needs identification and $A B C D$ are strategies of the locality development approach which emerged as enablers of spirituality in community settings. These strategies appeared as enablers of spirituality in communities which created a supportive environment whereby community members were able to take control of their lives and make decisions about their health and well-being. The current findings add substantially to our understanding of spiritual occupations such as singing hymns and saying prayers that are related to religious and belief systems of community members. These spiritual 
occupations are considered to be collective actions of communities that enhance occupational engagement. One of the more significant findings to emerge from this study is that spirituality appeared as the core element in communities where students gain their learning experiences as part of community fieldwork. Therefore, the findings of this study indicate that students and educators may need to be aware of their own spiritual needs and communities' spiritual needs. Additionally, these findings seem relevant to enhance students' and educators' understanding of the role of spirituality in the community. The current findings provide impetus and motivation for students and educators to be more spiritually sensitive to their own and others' needs while engaging in social contact with communities.

\section{REFERENCES}

I. Polatajko HJ, Townsend EA, CraikJ. Canadian Model of Occupational Performance and Engagement (CMOP-E). In Enabling Occupation II: Advancing an Occupational Therapy Vision of Health, Well-being, \& Justice through Occupation. Edited by Townsend EA, Polatajko HJ. Ottawa: CAOT Publications ACE. 2007: 22-36.

2. Duncan EAS. Foundations for practice in occupational therapy. (5th ed.). Churchill Livingstone: Elsevier. 20II.

3. Puchalski CM, Vitillo R, Hull SK, Reller N. Improving the spiritual dimension of whole person care: Reaching National and International Consensus. Journal of Palliative Medicine, 20I4; 17 (4): 642=656. DOI: 10.1089/jpm. 2014. 9427

4. Puchalski, CM. The role of spirituality in health care. BUMC Proceedings. 200I; 14: $352-357$.

5. Kennedy J, Stirling I. Innovation in spiritual care. The Scottish of Health Care Chaplain. 2013; 16(Special): 60-67.

6. Rhys G. Spirituality discussion: Relevance, benefits and application to primary care consultations. Primary Health Care. 20I4; 4, 4. http:// dx.doi.org/10.4172/2167-1079.1000178. Chile LM, Simpson G. Spirituality and community development: Exploring the link between the individual and the collective. Community Development Journal. 2004; 39(4): 318-33I.DOI: I0.1093/cdj/bsh029.

7. Murray I. Spirituality as a dimension of integrated community development. PhD Thesis. Stellenbosch University, South Africa. 2013.

8. Singh B. Integration of spirituality with community development for peace. Pannasastra University of Cambodia. 2007.

9. Chile LM. Positive health promoting environments as the basis for building healthy communities. Public Health Association New Zealand Conference: Tomorrow for Tomorrows People, 22-24 September 2010.

10. Watson R, Duncan M. Transformation through occupation: towards a prototype, Chapter 20. In Transformation through occupation. Edited by Watson R, Swart L. London, Whurr Publishers. 2004: 30I-3I8.

II. Spittles B. Fostering spirituality in community development: The role of soul. Spirituality and Health International. 2008; 9: 6-I5. DOI: 10.1002/shi.317.

12. Ver Beek KA. Spirituality: a development taboo. Development in Practice, 2000; 10(I): 31-43.

13. Department of Education. Education white paper 3: A programme for higher education transformation. Government Gazette No. 18207, I5 August 1997. Pretoria: Government Printers.

14. Watson R. A population approach to occupational therapy. South African Journal of Occupational Therapy, 20I3; 43(I): 34-3.

15. Adams F, Casteleijn D. New insights in collective participation: A South African perspective. South African Journal of Occupational Therapy. 20I4; 44(I): 8I-87.

16. McGrath M, Moldes IV, Fransen H, Hofstede-Wessels S, Lilienberg K. Community-University partnerships in occupational therapy education: A preliminary exploration of practice in a European context. Disability and Rehabilitation. 2014; 36(4): 344-352. DOI: 10.3109/09638288.2013.78822

17. Lauckner H, Pentland W, Paterson M. Exploring Canadian occupational therapists understanding of and experiences in community development. Canadian Journal of Occupational Therapy. 2007; 74(4): 314. DOI: 10.2182/cjot.07.005.

18. MacQueen KM, McLellan E, Metzger DS, Kegels S, Strauss RP, Scotti $R$, Blanchard L, Trotter R. What is community? An evidence-based definition for participatory public health. American Journal of Public
Health. 200I; 9I(12): 1929-1938.

19. Labonte, R. Community, community development and the forming of authentic partnership: Some critical reflections. In Community organising and community building for health. ( $2^{\text {nd }}$ ed.). Edited by Minkler M. New Brunswick. NJ: Rutgers; 1997: 88-102.

20. Lauckner $\mathrm{H}$. Conceptualising community development from an occupational therapy perspective: Three Canadian case studies. PhD. Queen's University, Kingston, Ontorio, Canada. 2010

21. Hess-April, L. Conceptualisations of occupational justice in community service practice in South Africa: A UWC Case Study. PhD Thesis. University of the Western Cape, Bellville. 2013.

22. Rothman J, Erlich JL, Tropman JE. Strategies of community intervention. Itasca: F.E. Peacock Publisher: 200 I.

23. Holmberg V, Ringsberg K. Occupational therapists as contributors to health promotion. Scandinavian Journal of Occupational Therapy. 20।4; 0: 1-8.

24. Lood Q, Haggldom-Kronlöf G, Dahlin-Ivanoff S. Health promotion programme design and efficacy in relation to ageing person with culturally and linguistically diverse backgrounds: A systematic review literature review. BMC. Health Services Research. I5, 560. DOI 10.1186/s/2913-015-1222-4.

25. Micallef $\mathrm{C}$. Community development as a possible approach for the management of diabetes mellitus focusing on physical activity lifestyle changes: A model proposed for Maltese people with diabetes. International Journal of Community Development. 20I5; 2(2): 30 - 40. DOI: 10.II634/23302879|402582.

26. Laverack G, Mohammadi NK. What remains for the future: strengthening community actions to become an integral part of health promotion practice. Health Promotion International, 201 I; 26(S2): ii258 - ii262.

27. World Health Organization. Ottawa Charter for Health Promotion. WHO, Geneva, 1986.

28. Polatajko HJ, Townsend EA, CraikJ. Canadian Model of Occupational Performance and Engagement (CMOP-E). In Enabling Occupation II: Advancing an Occupational Therapy Vision of Health, Well-being, \& Justice through Occupation. Edited by Townsend EA, Polatajko HJ. Ottawa: CAOT Publications ACE. 2007: 22-36.

29. Department of Occupational Therapy. Module descriptor for Community fieldwork process. University Calendar: for Faculty of Community and Health Sciences. University of the Western Cape. 2016: 277.

30. De Jongh J. An innovative curricula change to enhance occupational therapy student practice. South African Journal of Occupational Therapy. 2009; 39(I): 31-38.

3I. Vermeulen N, Amod A, Bell T, Cloete A, Johannes T, Williams K. Students' fieldwork experiences of using community entry skills with community development. South African Journal of Occupational Therapy. 2015; 45(2): 5I-55. DOI: http://dx.doi.org/10.17/59/2310$3833 / 2015 / v 45 n 2 a 8$.

32. Vermeulen $N$. Final year occupational therapy students' experiences of supervision during community fieldwork practice. Masters Thesis, University of the Western Cape, Bellville. 2012.

33. Tareen EU, Abu Omar M. Community entry: An essential component of participation. Health Manpower Management. 1997; 23(3): 97-99.

34. Hopkins T, Rippon S. Head, hands and heart: asset-based approaches in health care. London: Health Foundations. 2015.

35. Kang, C. A psychospiritual integration frame of reference for occupational therapy. Part I: Conceptual foundations. Australian Occupational Therapy Journal. 2003; 50: 92-103.

36. Griffith J, Caron CD, Desrosiers J, Thibeault R. Defining spirituality and giving meaning to occupation: The perspective of communitydwelling older adults with autonomy loss. Canadian Journal of Occupational Therapy. 2007; 74(2): 78-90.

37. $\mathrm{Di} X$. Spiritual heritage and education today. International Journal of Humanities and Social Science. 20I 3; 3(I): 42-5I.

38. Grove SK, Burns N, Gray JR. The Practice of nursing Research: Appraisal, Synthesis, and Generation of Evidence, (7th ed.). Saunders: Elsevier. 2013.

39. Rowlands BH. Grounded in Practice: Using Interpretive Research to Build Theory. The Electronic Journal of Business Research Methodology. 2005; 3(I): 8I-92.

40. Hall HR, Roussel LA. Evidence-Based Practice: An integrative ap- 
proach to research, administration and practice. Jones \& Barlett Learning. 2014.

4I. Braun V, Clarke V. Using thematic analysis in psychology. Qualitative Research in Psychology. 2006; 3(2): 77-I0I.

42. Friese S. Qualitative data analysis with Atlas.ti. ( $2^{\text {nd }}$ ed.). London: SAGE Publications Ltd. 2014.

43. Krefting $L$. Rigor in qualitative research: The assessment of trustworthiness. American Journal of Occupational Therapy. 1991; 45(3): 2I4-222.

44. Phillips $C$. Spirituality and social work: Introducing a spiritual dimension into social work education and practice. AOTEAROA New Zealand Social Work. 20I4; 26(4): 65-77.

45. Knudson S. Integrating the Self and the Spirit: Strategies for Aligning Qualitative Research Teaching with Indigenous Methods, Methodologies, and Epistemology [64 paragraphs]. Forum Qualitative Sozialforschung / Forum: Qualitative Social Research. 2015; 16(3): Art. 4, http://nbn-resolving.de/urn:nbn:de:0I I 4-fqs I 50347.

46. Wilding C, May E, Muir-Cochrane E. Experience of spirituality, mental illness and occupation: A life-sustaining phenomenon. Australian Occupational Therapy Journal. 2005; 52: 2-9.

47. Arrey AE, Bilsen J, Lacor P, Deschepper R Spirituality/Religiosity: A Cultural and Psychological Resource among Sub-Saharan African Migrant Women with HIV/AIDS in Belgium. PLoS ONE. 2016; I I (7): e0I59488. doi:I0.137I/journal. pone.0159488.

48. McCaskill W. Random Acts of Kindness. 2010. https://www.playistheway.com.au/img/cms/Random\%20Acts\%20of\%20Kindness. pdf. Date: 27 July 2016.

49. Louw DJ. Ubuntu: an African assessment of religious other. Twentieth World Congress of Philosophy.

\section{Corresponding Author}

\section{Thuli G Mthembu}

Occupational Therapy Department,

University of the Western Cape,

Private Bag XI7, Bellville, 7535.

Email: tmthembu@uwc.ac.za, tgmthembu@gmail.com 